\title{
Knowledge and practice of preparedness for infectious disease prevention and control among healthcare workers in secondary health care facilities in Osogbo, Nigeria
}

Adebimpe $\mathrm{WO}^{1}$, Adabanija $\mathrm{K}^{2}$ and Ibirongbe $\mathrm{DO}^{1}$.

${ }^{1}$ Department of Community Medicine, University of Medical Sciences, Ondo, Nigeria

${ }^{2}$ Department of Community Medicine, LAUTECH College of Health Sciences Osogbo Nigeria

Correspondence: Adebimpe WO.+234 8033712662 Email: lekanadebimpe@gmail.com

\begin{abstract}
Background: Health care workers have critical roles to play in breaking the chain of infections in health care settings. The outbreak of Lassa Fever and Ebola Virus Disease in the West African sub-region in recent times is a rationale for a dire need for a strong epidemic preparedness system. The objective of the study is to assess the knowledge and practice of preparedness for infectious disease prevention and control among healthcare workers in secondary health care facilities in Osogbo, Nigeria.

Methods: It was a Descriptive cross sectional study and 340 healthcare workers were selected using a multistage sampling technique. Research instrument used were semi structured pre-tested intervieweradministered questionnaire. Data was analyzed using the SPSS software version 17.0 .
\end{abstract}

Results: The mean age of the respondents was $42 \pm 8.9$ years. Out of the 340 healthcare workers studied $88.7 \%$ had good knowledge, while $72 \%$ and $67 \%$ had favorable attitude and good practice towards preparedness for infectious disease prevention and control respectively. Three hundred and eight (90.6\%) said they washed their hands regularly before and after procedures. Only $37.4 \%$ said they still recap used needles and $31.8 \%$ said they have Infectious Disease Prevention and Control committee in their health facility. One hundred and ninety eight (58.2\%) said they normally practice quarantine for eligible suspected cases and $77.4 \%$ perceived themselves to be at occupational risk of contracting infectious diseases. Having more than ten years of working experience was the major predictor of likelihood to have good knowledge, attitude and practice of preparedness on binary logistic regression analysis.

Conclusion: The gap between knowledge and practice of preparedness for Infectious Disease and prevention Control calls for improved awareness and training among health workers, and their consistent monitoring towards behavioural change.

Key words: Infectious disease, preparedness, control, health care workers 
Introduction

Communicable diseases outbreak had been a threat not only to lives of individuals but also national security. The recent and ongoing outbreak of Lassa Fever and Ebola Virus Disease in some parts of Africa stressed the urgent need to break the chain of infections through universal standard precaution, and this should be the responsibility of all health care workers. Studying epidemic outbreaks could galvanize support towards building capacities to meet the requirements of the international health regulations. ${ }^{1}$ It is possible to track outbreaks of diseases and step up medical treatment and preventive measures even before it spreads over a large populace. ${ }^{2}$ Appropriate disease surveillance system should adequately identify, define and recognize cases of illness on a timely and complete basis; and culminating into data driven forecast and advice on the trend of infections. ${ }^{3}$ Nigeria need to identify gaps in her surveillance systems towards timely and complete reporting of all diseases in order to meet up with international standards in surveillance program.

Health care workers are traditionally known to be in close proximity with patients, and are likely to be at high risk of acquiring from and transmitting infectious disease to others. Worldwide, almost 3 million Health Care Workers (HCWs) experiences percutaneous exposure to blood-borne pathogens each year, though situation is better in developed than in the developing countries. ${ }^{4}$ In developing countries including Nigeria, the culture of preparedness for infectious disease control before its eventual outbreak is poor compared to the pattern in developed countries. Tracking of the pattern of infectious diseases could assist preparedness for control and also preventive measures that could be instituted even before it spreads over a large populace. ${ }^{4}$

Health care workers both at health facility and community, have significant roles to play in preventing disease outbreaks in the health-care and related settings. ${ }^{5}$ They can also assume the leadership role in creating awareness and instituting prevention efforts; and this would largely depend on the level of their acquiring good knowledge and positive attitudes. ${ }^{6}$

Poor practice of universal precaution among Nigeria health workers, ${ }^{7,8}$ had been reported, though practice of universal precaution had improved over the years. ${ }^{9}$ Thus there is a need for every country level institution to coordinate preparedness, detection and timely response to public health emergencies. This would be feasible when the capacity of health care workers is built in the areas of prevention and preparedness, in terms of knowledge and practices. The general objective of this study was to assess the knowledge and practice of preparedness for infectious disease prevention and control among healthcare workers in primary health care facilities in Osun state in Southwestern Nigeria.

\section{Methods}

Osogbo where this study was carried out is the capital city of Osun State in the southwestern region of Nigeria with a population of about $300,000 .{ }^{10}$ There is a teaching hospital, two general hospitals, and about twenty primary health care facilities in the city, delivering health services. This study was a descriptive cross-sectional design. The subjects were health care workers in secondary health care facilities in Osun state who must have put at least one year into the practice as at the time of this study. There are two secondary health facilities within Osogbo, and these include Jaleyemi missionary 
hospital which is privately owned, and Asubiaro general hospital which is owned by Government. Using Leslie Fisher's formular, the calculation of minimum sample size for single proportion, a figure of 303 was estimated based on an infection preparedness prevalence value of $27.0 \%{ }^{11}$

The total sample size was increased to 340 after correction for non-response. Subjects were selected using multistage sampling technique. The State hospital at Asubiaro, Osogbo was selected by balloting while four categories of health care workers namely Doctors, Lab Scientists, Nurses, and Community health workers in the different units were also selected by balloting after proportionate allocation of sampling units. From the sampling frame obtained for each category a systematic sampling was applied until the total sampling unit for that category was obtained. Self administered semistructured pre-tested questionnaire was used. The research assistants explained the purpose of the study to respondents and obtained their written consent before the questionnaires were administered.

The obtained data were analyzed using Statistical Package for Social Sciences (SPSS) version 17.0. Knowledge score was computed for a pooled knowledge questions on various aspects of infectious diseases preparedness, prevention and control. Each item was assigned " +1 " for correct knowledge and " 0 " for incorrect knowledge. The knowledge score was graded as good or appropriate if respondent scored above; and poor or not appropriate if scored below the mean score as the break-off point. The attitude of the respondents was graded on Likert scale with "agree" scoring 2, "indifferent" scoring 1 and "disagree" scoring 0 . Respondent that has a score less than half of the total score were identified as having a poor attitude while those that score above average were identified as having a good attitude. Questions of preparedness with overall preparedness score of 8 (ranged from 0 to 8 ) were given (yes, no or sometimes) option against each set of question, were dichotomized to good preparedness ( 1 point) with score $\geq 5$ or poor preparedness ( 0 point) with score $<5$.

Association between categorical variable was measured using Chi-square. Multivariate analysis was performed using logistic regression to evaluate sociodemographic variables and other variables that are independently associated with good knowledge and practice score of infectious diseases prevention and preparedness. P-values were considered significant at values equal to or less than 0.05 .Ethical clearance was obtained from LAUTECH Teaching Hospital ethical review board.

\section{Results}

Table 1 shows respondents average age of $42 \pm 8.9$ years, $86.2 \%$ were female, $70.0 \%$ were married, $47.4 \%$ were nurses while $68.2 \%$ had $1-10$ years working experience. Figure 1 shows $88.7 \%, 86.5 \%, 94.1 \%$ and $55.1 \%$ had good knowledge on preparedness for prevention and control of infectious disease, signs and general symptoms of common infectious disease, treatment and prevention of infectious disease, and infectious disease reporting respectively. Table 2 shows $90.6 \%$ of the respondents said they washed their hands regularly before and after procedures/wearing gloves, while $37.4 \%$ said they still recap used needles and $31.8 \%$ said they had infectious disease control committee in their health facility/LGA, 58.2\% said they normally practice quarantine for eligible suspected cases, $67.9 \%$ said they were willing to be part of epidemic investigation team, $66.2 \%$ 
said their health care facility was well equipped to handle infectious diseases outbreaks while 56.8 of respondents said they were adequately trained on infectious disease prevention, control and preparedness. Two hundred and sixty three $(77.4 \%)$ of respondents perceived themselves to be at risk of contracting infectious disease due to the nature of their work.

Figure 2 shows $72.0 \%$ of respondents had favorable attitude towards prevention and preparedness for infectious disease control. In addition, only $67.0 \%$ of respondents had good practice while $33.0 \%$ had poor practice. Table 3 displayed no statistical significant association between working experience and knowledge $(\mathrm{P}>0.05)$, but such association exists between working experience and attitude and practice of epidemic preparedness $(p<0.05)$. Likewise a statistically significant association was found between gender and attitude to epidemic preparedness $(p<0.05)$. On binary logistic regression analysis, respondents with 1-10 years working experience were about four times (1/0.24) times less likely to have good knowledge of epidemic preparedness compared to those with more than ten years experience, and this observation was found to be statistically significant (OR $0.24,95 \% \mathrm{CI}$ 0.066-1.093, $\mathrm{p}=0.200)$. Respondents with 1-10 years working experience are two and a half times (1/0.32) times less likely to have good attitude of epidemic preparedness compared to those with more than ten years experience, and this observation was found to be statistically significant (OR 0.39, 95\% CI 0.192-0.802, $\mathrm{p}=0.004)$.

Male respondents were two and a half $(1 / 0.37)$ times less likely to have good attitude to epidemic preparedness compared to those with more than ten years experience, and this observation was found to be statistically significant (OR 0.39, 95\%CI 0.192-0.802, p 0.004). Respondents with 1-10 years working experience are three (1/0.32) times less likely to have good practice of epidemic preparedness compared to those with more than ten years experience, and this observation was found not to be statistically significant (OR $0.37,95 \% \mathrm{CI}$ $0.125-1.069$, p 0.066). Thus predictor of good knowledge, attitude and practice of epidemic preparedness was having a working experience of more than ten years. Female gender was a predictor of good attitude to epidemic preparedness. 
Table 1: Socio demographic information of respondents $(n=340)$.

\begin{tabular}{lc}
\hline Information & Freq.(\%) \\
\hline Age (Mean $42+8.9)$ years & \\
$20-29$ years & $98(28.8)$ \\
$30-39$ years & $52(15.3)$ \\
$40-49$ years & $162(47.7)$ \\
$50-59$ years & $28(8.2)$ \\
& \\
Sex $\quad$ & $47(13.8)$ \\
$\quad$ Male & $293(86.2)$ \\
Female & \\
Marital status & $97(28.5)$ \\
Single & $238(70.0)$ \\
Married & $5(1.5)$ \\
Separated/divorced & 0 \\
Widow & \\
Highest Educational qualification & $12(3.5)$ \\
NCE & $239(70.3)$ \\
B.Sc. & $70(20.6)$ \\
PGD & $19(5.6)$ \\
M.Sc. & \\
Disciplines & $26(7.6)$ \\
Medicine/doctors & $161(47.4)$ \\
Nursing & $57(16.8)$ \\
Medical Lab science & $96(28.2)$ \\
Community Health workers & \\
Working experience & $232(68.2)$ \\
1 - 10 years & $66(19.4)$ \\
11 - 20 years & $42(12.4)$ \\
\hline
\end{tabular}
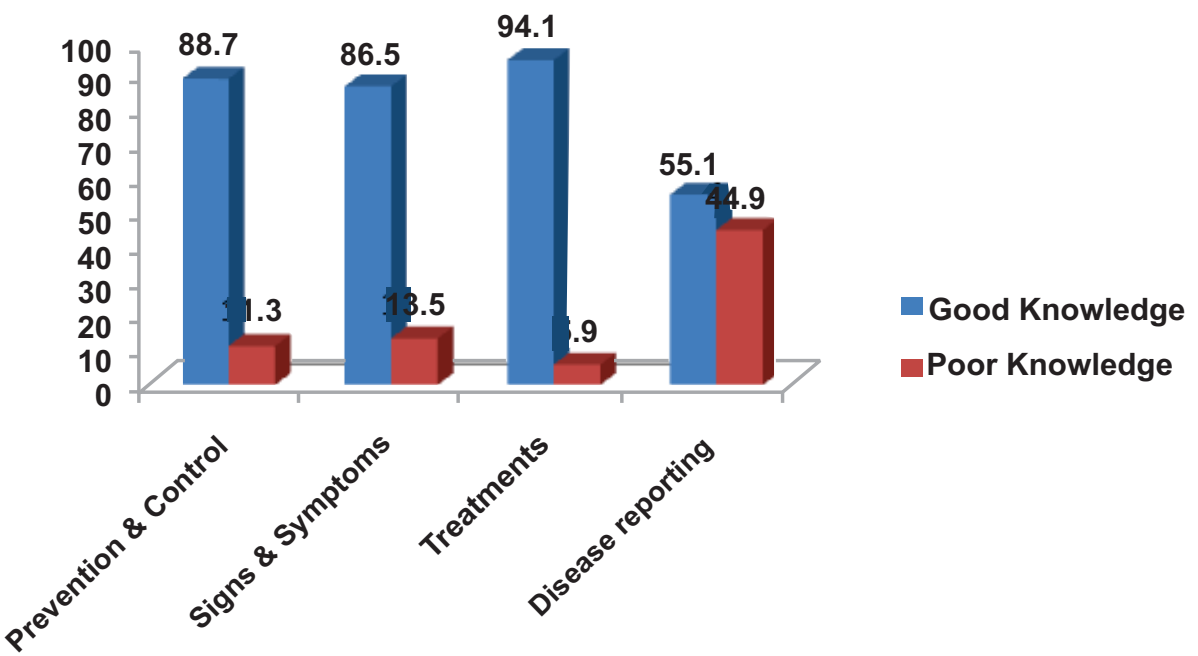

Figure 1: Mean scores of knowledge of prevention and control of infectious diseases. 
Table 2: Preparedness of practice by health care workers towards infectious disease.

\begin{tabular}{|c|c|c|}
\hline Questions & $\begin{array}{c}\text { Yes } \\
\text { Freq. (\%) }\end{array}$ & $\begin{array}{c}\text { No } \\
\text { Freq. (\%) }\end{array}$ \\
\hline Do you wash your hand regularly before and after wearing the gloves & $308(90.6)$ & $13(3.8)$ \\
\hline Do you recap needle after use & $190(55.9)$ & $127(37.4)$ \\
\hline Is your health care facility well equipped to handle infectious disease cases & $225(66.2)$ & $83(24.4)$ \\
\hline $\begin{array}{l}\text { Do you have an inf ectious disease control committee in your hospital or } \\
\text { does it exist at LGA level }\end{array}$ & $108(31.8)$ & $185(54.4)$ \\
\hline $\begin{array}{l}\text { Do you normally do outreaches sessions to enlighten public about infectious } \\
\text { disease prevention and control }\end{array}$ & & $33(9.7)$ \\
\hline Do you normally practice quarantine for eligible suspected cases & $198(58.2)$ & $67(19.7)$ \\
\hline Has there ever been epidemic of any disease within your locality before & $90(26.5)$ & $166(48.8)$ \\
\hline Was the epidemic investigated & $71(20.9)$ & $68(20.0)$ \\
\hline Are you willing to be part of epidemic investiga tion team & $231(67.9)$ & $49(14.4)$ \\
\hline Would you say your health facility is ready to contain epidemic outbreaks & $161(47.4)$ & $123(36.2)$ \\
\hline Are you adequately trained on infectious disease prevention and control & $193(56.8)$ & $106(31.2)$ \\
\hline
\end{tabular}

"Not sure" column not shown

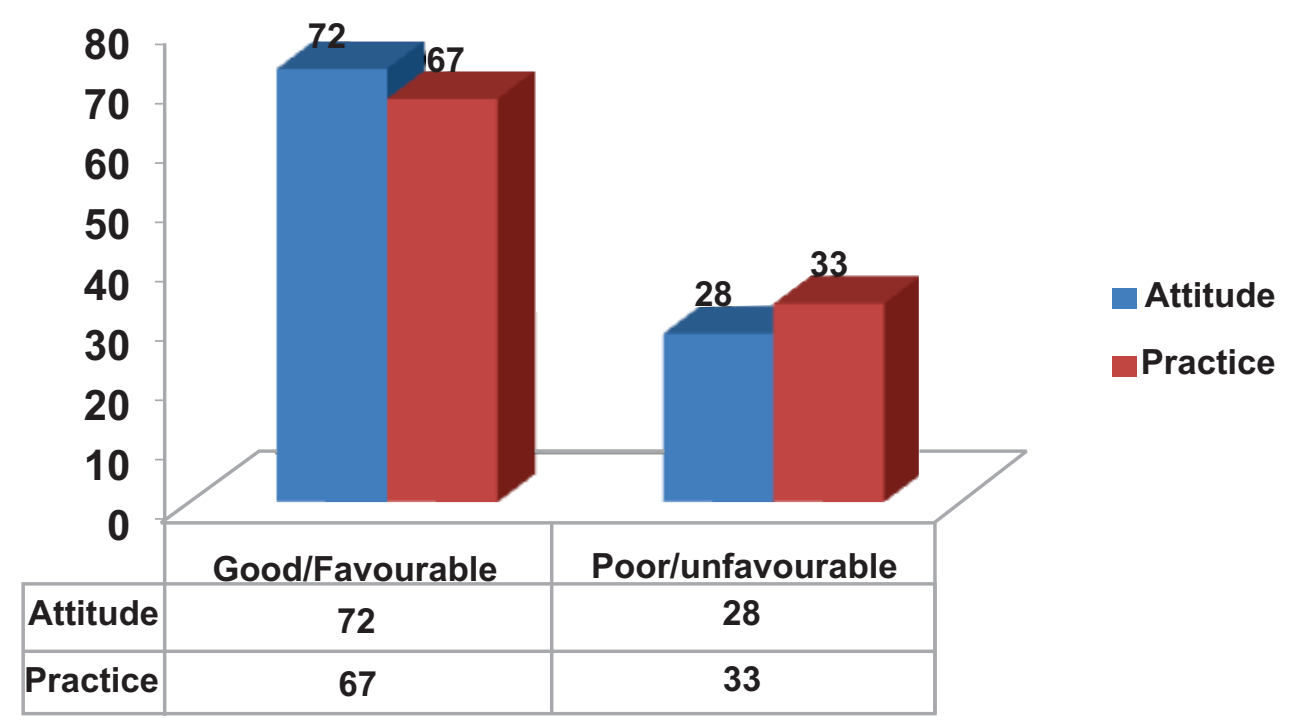

Figure 2: Mean attitude and practice score of respondents on preparedness for prevention and control of infectious disease. 
Table 3: Association between Respondent's gender, work experience and knowledge, attitude and practice of preparedness

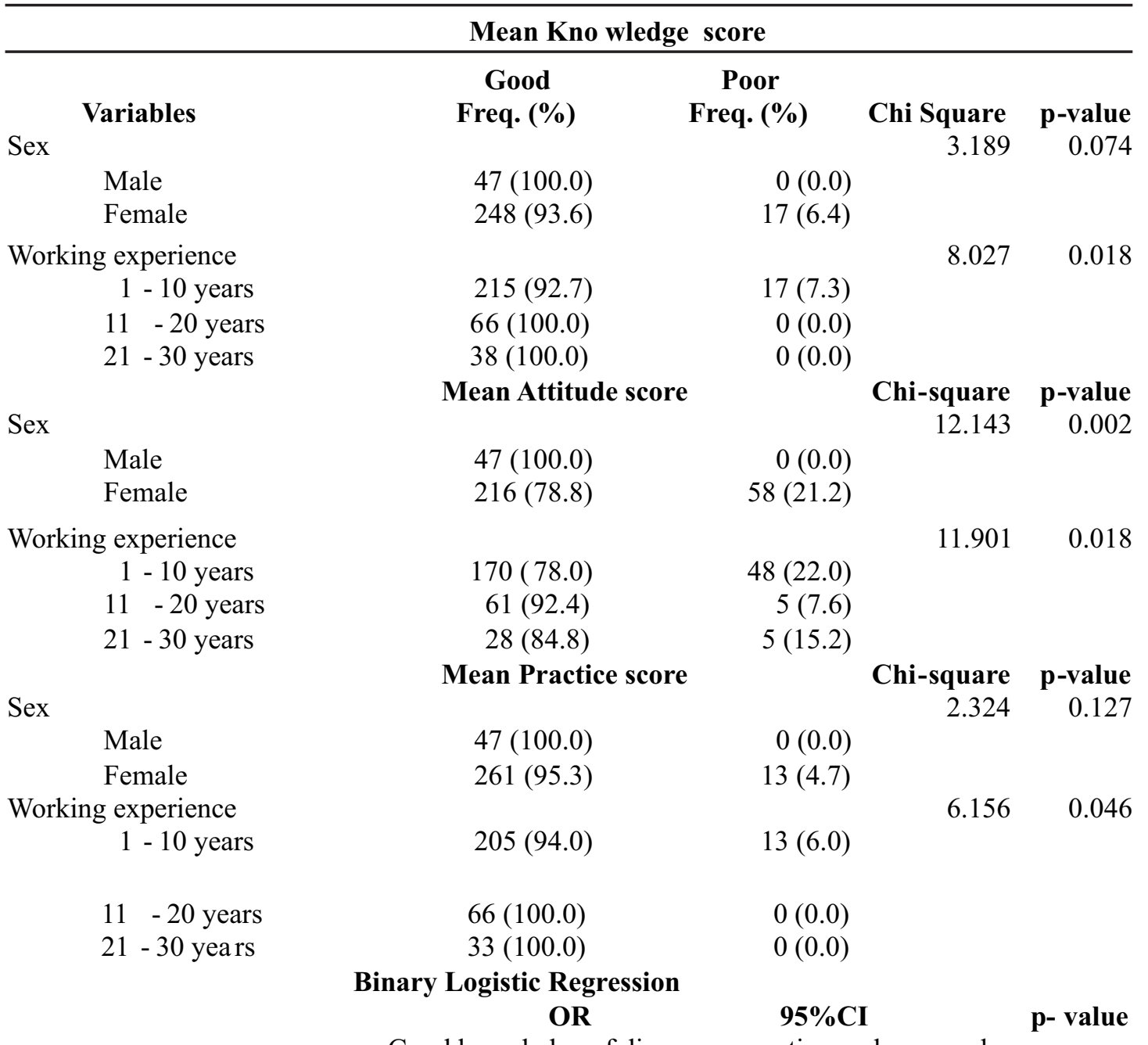

Workin g experience (Reference

Good knowledge of disease prevention and preparedness

Category $=1-10$ years)

$\begin{array}{llll}0.24 & 0.066 & 1.093 & 0.200\end{array}$

Gender $($ Reference Category $=$

Favourable attitude to disease prevention and preparedness

female)

$\begin{array}{llll}0.37 & 0.125 & 1.069 & 0.066 \\ 0.39 & 0.192 & 0.802 & 0.004\end{array}$

Working experience (Reference

Category $=1-10$ years)

Good practice of disease prevention and preparedness

Working experience (Reference

$\begin{array}{lll}0.32 & 0.072 & 1.469\end{array}$

0.063

Category $=1-10$ years)

Discussions

In this study, good knowledge of prevention and preparedness for infectious disease control, signs and general symptoms of common infectious disease, treatment and prevention of infectious disease was found among majority of respondent. Similar high knowledge was found in other studies. ${ }^{12,13}$ A much lower figure were obtained in a study in which the 
level of knowledge on infection control was described as good among a little more than half of respondents. ${ }^{14}$ In yet another study, only two-fifth had good knowledge while only about one quarter knew that there was no vaccine presently to prevent EVD. ${ }^{15}$ The discrepancy might be due to the differences in study setup and methods. However, having a good knowledge is a pointer to ones attitude and practice of the subject matter.

Good knowledge of infectious disease reporting was reported in only among half of respondents in our study. This is similar to study having similar pattern of undernotification ${ }^{16}$ Though reporting is an important aspect of disease outbreak management and response, underreporting of notifiable diseases is a common problem for passive surveillance systems in many countries. ${ }^{17}$ Majority of our respondents said they washed their hand regularly before and after procedures. This supports another study that majority (about 91\%) reported hand washing with soap and water and $64 \%$ for alcohol based rub. ${ }^{18}$ Hand hygiene in form of hand washing with soap and water has long been considered one of the most important IDPC measures. ${ }^{19}$ A little over one third said they still recap used needles in our study, this supports a study in which about a third of participants recapped used needles, ${ }^{20}$ and another study where about a third also always recapped used needles while a little less than two-thirds of respondents always used personal protective equipment. $^{21}$ In yet another study, about a quarter of the respondents do not recap needles after use. ${ }^{22}$ These findings implies poor practice of injection safety among these respondents. There is a need to train all health workers on injection safety and standard precaution in infectious disease prevention and control.
In our study, a little less than one third $(31.8 \%)$ said they had infectious disease control committee in their health facility/LGA, This agreed with another study in which a little over one quarter of respondents sometimes promptly wipe all blood spills, ${ }^{22}$ but lower when compared to another study in which about three-fifths said they normally practice quarantine for eligible suspected cases. ${ }^{23}$ In another similar study, the vast majority of the HCWs self-reported that they perform the disinfection in their working activity. ${ }^{24}$ There is a need for establishment of infectious disease preparedness and control teams or committees in all health facilities and provision of appropriate resources to manage infectious disease outbreak.

About two thirds of our study participants said they were willing to be part of epidemic investigation team. This is a favourable trend since effective preparedness and then quick and efficient response to infectious disease emergencies and outbreaks depends on the ability and willingness of the public health workforce to respond ${ }^{25}$ However, the implementation of this favourable submission from the health care workers could be hampered by the result of our study that reported that about another two thirds (66.2) said their health care facility was well equipped to handle infectious diseases. This is also similar to findings in a study where almost two-third of the respondents identified lack of appropriate or adequate resources to practice standard precautions as a challenge to practice of standard precaution in disease prevention. ${ }^{20}$

A little over half of the respondents said they were adequately trained on infectious disease prevention and control and preparedness. This indicate a dire need for training healthcare professionals on public 
health management of infectious disease emergencies, as it was done during SARS epidemic, the threat of bioterrorism and other outbreaks in Europe. ${ }^{26}$ Majority of our study participants perceived themselves to be at risk of contracting infectious disease, This pattern supports another study in which only about onequarter had low risk perception, while about two-fifth considered self to be at risk of EVD ${ }^{15}$ However, another study reported that HCWs were assessed to have underestimated their likelihood for contracting Ebola compared to their colleagues of same age and sex. ${ }^{27}$ Perception, especially perceived risk of disease could determine attitude to and practice of infectious disease prevention and control among health workers. Majority of our respondents having favorable attitude towards prevention and preparedness for infectious disease control supports another study. ${ }^{28}$ However, two thirds having good practice of preparedness is better when compared to a similar study on infectious disease that reported unsatisfactory practice score towards tuberculosis infection control in about half of their respondents. ${ }^{29}$

Our study reported predictors of good knowledge, attitude and practice of epidemic preparedness as having a working experience of more than ten years, while being a female was a predictor of good attitude to epidemic preparedness. In a similar study, having more than six years working experience in health facility and having been trained on infectious diseases were significantly associated with knowledge on tuberculosis infection control. ${ }^{29}$ This predictor is not unexpected since respondents who have spent considerable number of years on service should have attended quite a number of trainings, and would have had more on the job experience compared to the newly recruited.

\section{Conclusion}

Though high awareness of IDPC was reported in this study, attitude was lower while practice was much more lower compared to knowledge of IDPC. The gap existing between knowledge and practice of preparedness for IDPC calls for improved awareness among health care workers, while formal and on the job training could be organized to bridge the gap between knowledge and practice of IDPC with consistent monitoring of their activities towards a positive behavioural change.

\section{References}

1. The World Health Organization. "International Health Regulations Procedures concerning public health emergencies of international concern (PHEIC) 2009.Date accessed July 12, 2018. Available at http://www.who.int/ihr/procedures/p heic/en/.

2. Yangarber R, Jokipii L, Rauramo A, Huttunen S. Extracting information about outbreaks of infectious epidemics. Vancouver, Canada: In Proc HLT-EMNLP; 2005; 7:57-64.

3. WHO. Communicable Disease Surveillance and Response (CSR) 2009. Available from :http://www.who.int/emc/surveill/ind ex.html[Last accessed on July 12 2018.

4. World Health Organization. The World Health Report 2012:

Reducing Risks, Promoting Healthy Life, Geneva, Switzerland: World Health Organization; 2012.Available at https://www.who.int/whr/2002/en/. Accessed $18^{\text {th }}$ July 2018

5. Hampton T. H1N1 vaccine urged for health workers, but some resist getting on board. JAMA, 2009; 302: 848-849. 
6. Lemaitre M, Meret T, RothanTondeur M, Belmin J, Lejonc JL, Luquel L et al. Effect of influenza vaccination of nursing home staff on mortality of residents: a clusterrandomized trial. J Am Geriatr Soc, 2009; 57: 1580-1586.

10.1111/j.1532-5415.2009.02402.x.

7. Adinma ED, Ezeama C, Adinma JIB, Asuzu MC. Knowledge and practice of universal precautions against blood borne pathogens amongst house officers and nurses in tertiary health institutions in Southeast Nigeria. Nigerian Journal of Clinical Practice, 2009; 12: 398-402Sadoh

8. WE, Fawole AO, Sadoh AE, Oladimeji AO and Sotiloye OS. Practice of universal precautions among healthcare workers. J Natl Med Assoc, 2006; 98(5): 722-726. Amoran

9. OE, Onwube OO. Infection Control and Practice of Standard Precautions Among Healthcare Workers in Northern Nigeria.J Glob Infect Dis, 2013; 5(4): 156-163

10. National Population Commission [Nigeria]. Nigeria Demographic and Health Survey. Calverton, Maryland: National Population Commission and ORC Macro; 2006:45-7.

11. Janjua NZ, Razaq M, Chandir S, Rozi S, Mahmood B. Poor knowledge predictor of nonadherence to universal precautions for blood borne pathogens at first level care facilities in Pakis tan. BMC Infectious Diseases. 2007,7:81-5

12. Temesgen C. Knowledge and practice of tuberculosis infection control among health professionals in Bahir Dar, West and East Gojjam zone Hospital; Northwest Ethiopia. BMC Health Serv Res, 2011;
14:593. doi: 10.1186/s12913-0140593-2.

13. Hashim DS, Al Kubaisy W, Al Dulaym A. Knowledge, attitudes and practices survey among health care workers and tuberculosis patients in Iraq. East Mediterr Health J,2003; 9(4):718-31. Shrestha

14. A, Bhattarai D, Thapa B, Basel P and Raj WagleR. Health care workers' knowledge, attitudes and practices on tuberculosis infection control, Nepal. BMC Infect Dis, 2017; 17: 724. doi: 10.1186/s12879017-2828-4Olowookere

15. SA, Abioye-Kuteyi EA, Adepoju OK, Esan OT, Adeolu TM and Adeoye TK et al. Knowledge, Attitude, and Practice of Health Workers in a Tertiary Hospital in IleIfe, Nigeria, towards Ebola Viral Disease. J Trop Med, 2015; 431317. doi: $10.1155 / 2015 / 431317$

16. Leman AM, Omar AR, Rahman KA, Zainal M. Reporting of occupational injury and occupational disease: current situation in Malaysia. (Injury and disease reporting systems). Asian-Pacific Newsletter on Occupational Health and Safety; Helsinki, Finland, 2010; 17(2): 1-6

17. Ibarz-Pavon AB, Papaventsis D, Kalkouni R, Metaxas G, Spala G, Georgakopoulou T, et al. Pilot study of the completeness of notification of adult tuberculosis in Athens, Greece. Int J Tuberc Lung Dis, 2016; 20(7):920-5. Epub 2016/06/12. pmid:27287645. Anargh

18. V, Singh H, Kulkarni A, Kotwal A and Mahen A. Air Cmde. Hand hygiene practices among health care workers (HCWs) in a tertiary care facility in Pune. Med J Armed Forces India, 2013; 69(1): 54-56. doi: 10.1016/j.mjafi.2012.08.011 
Mani A

19. Shubangi AM, Saini R. Hand hygiene among health care workers. Indian J Dent Res., 2010; 21(1):1158. doi: 10.4103/0970-9290.62810.

20. Ogoina D, Pondei K, Adetunji B, Chima G, Isichei C, Gidado S. Knowledge, attitude and practice of standard precautions of infection control by hospital workers in two tertiary hospitals in Nigeria. Journal of Infection Prevention,2015; 16(1) $16-22$

21. Adebimpe, WO. Knowledge, Attitude, and Practice of Use of Safety Precautions Among Health Care Workers in a Nigerian Tertiary Hospital, 1 Year After the Ebola Virus Disease Epidemic, Annals of Global Health, 2016; 82 (5): 897902

22. Akapgbo SE, Nortey P and Ackumey MM. Knowledge of standard precautions and barriers to compliance among healthcare workers in the Lower Manya Krobo District, Ghana. BMC Research Notes, 2017; 10:432

Suliman M

23. Aloush S, Aljezawi M, AlBashtawy M.Knowledge and practices of isolation precautions among nurses in Jordan. Am J Infect Control.2018; 46(6):680-684. doi: 10.1016/j.ajic.2017.09.023.

24. Luciana AL, Matuozzo A, Marinelli $P$ and Di Giuseppe G. Knowledge, attitudes and behaviour of hospital health-care workers regarding influenza $\mathrm{A} / \mathrm{H} 1 \mathrm{~N} 1$ : a cross sectional survey. BMC Infectious Diseases, 2014; 14:208-216

25. McCabe OL, Barnett DJ, Taylor HG, Links JM. Ready, willing, and able: a framework for improving the public health emergency preparedness system. Disaster Med Public Health Prep, 2016; 4(2):161168Baka A

26. Fusco FM, Puro V, Vetter N, Skinhoj $\mathrm{P}$, Ott $\mathrm{K}$ et al. A curriculum for training healthcare workers in the management of highly infectious diseases. Euro Surveill., 2017; 1;12(6):E5-6.Sridhar

27. S, Brouqui P, Fontaine J, Perivier I, Ruscassier P and Gautret $P$ et al. Risk perceptions of MSF healthcare workers on the recent Ebola epidemic in West Africa. New Microbes New Infect, 2016; 12: 61-68. doi: 10.1016/j.nmni.2016.04.010 Brisibe

28. SFA, Ordinioha B and Gbeneolol PK.. Knowledge, attitude, and infection control practices of two tertiary hospitals in Port-Harcourt, Nigeria .Journal, 2014; 17(6):691695 Gizaw

29. DG, Alemu ZA, and Kibret KT. Assessment of knowledge and practice of health workers towards tuberculosis infection control and associated factors in public health facilities of Addis Ababa, Ethiopia: A cross-sectional study. Arch Public Health, 2015; 73(1): 15. doi: 10.1186/s13690-015-0062-3 